University of Wollongong

Research Online

Faculty of Social Sciences - Papers (Archive) Faculty of Arts, Social Sciences \& Humanities

2013

The influence of the social context on students in-class physical activity

Dana J. Perlman

University of Wollongong, dperlman@uow.edu.au

Follow this and additional works at: https://ro.uow.edu.au/sspapers

Part of the Education Commons, and the Social and Behavioral Sciences Commons

Research Online is the open access institutional repository for the University of Wollongong. For further information contact the UOW Library: research-pubs@uow.edu.au 


\title{
The influence of the social context on students in-class physical activity
}

\begin{abstract}
The purpose of this study was to examine the influence of the social context, based within selfdetermination theory, on student's in-class physical activity. A total of 84 Year 11/12 physical education students were randomly assigned to one of three treatment groups; Autonomy-supportive, Controlling and Balanced. Data were collected using a pretest/posttest design measuring in-class physical activity. Analysis of data used Repeated Measures ANOVAs to examine group differences. Results indicated significant differences for students engaged in the autonomy-supportive context in terms of moderate-tovigorous physical activity. These results indicate that instructional behaviors that align with an autonomysupportive context can facilitate higher levels of in-class physical activity.
\end{abstract}

\section{Keywords}

physical, context, activity, social, influence, students, class

\section{Disciplines}

Education | Social and Behavioral Sciences

\section{Publication Details}

Perlman, D. J. (2013). The influence of the social context on students in-class physical activity. Journal of Teaching in Physical Education, 32 (1), 46-60. 


\title{
The Influence of the Social Context on Students In-Class Physical Activity
}

\author{
Dana Perlman \\ University of Wollongong
}

\begin{abstract}
The purpose of this study was to examine the influence of the social context, based within self-determination theory, on student's in-class physical activity. A total of 84 Year 11/12 physical education students were randomly assigned to one of three treatment groups; Autonomy-supportive, Controlling and Balanced. Data were collected using a pretest/posttest design measuring in-class physical activity. Analysis of data used Repeated Measures ANOVAs to examine group differences. Results indicated significant differences for students engaged in the autonomy-supportive context in terms of moderate-to-vigorous physical activity. These results indicate that instructional behaviors that align with an autonomy-supportive context can facilitate higher levels of in-class physical activity.
\end{abstract}

Keywords: physical activity, social context, self-determination theory

The concept of physical activity (PA) is and has been a hot topic within the physical education literature. The high level of interest toward PA within physical education can be attributed to the strong connection with the wide array of physiological and emotional health benefits (Watts, Jones, Davis, \& Green, 2005). Furthermore, the United States Department of Health and Human Services (2010) calls upon physical education as a medium for engaging students in health-enhancing PA, commonly termed moderate-to-vigorous physical activity (MVPA). As such, research in physical education is interested in understanding techniques and instructional behaviors that influence student's in-class PA. An area that has demonstrated promise toward influencing the aforementioned goal (i.e., in-class physical activity) is the social context (Lim \& Wang, 2009; Ryan, Williams, Patrick, \& Deci, 2009).

\section{Social Context}

The social context plays an integral part within the teaching and learning domain. Grounded within self-determination theory (Deci \& Ryan, 1985), the social context involves primarily environmental factors, commonly manipulated by the teacher in educational settings, which influence students' desire or motivation (Deci \&

Perlman is with the Faculty of Education, University of Wollongong, Wollongong, New South Wales, Australia. 
Ryan, 1985; Vallerand \& Losier, 1999). Furthermore, the influence on motivation has ramifications for students' engagement in physically active behaviors (Hagger, Chatzisarantis, Barkoukis, Wang, \& Baranowski, 2005; Pihu, Hein, Koka, \& Hagger, 2008; Vallerand \& Losier, 1999). Aspects of the social context have been identified as facilitating a variety of positive student outcomes and experiences, including higher attendance rates (Edmunds, Ntoumanis, \& Duda, 2006), motivation (Perlman, 2011a, 2011b; Perlman \& Goc Karp, 2010), leisure time PA (Hagger, Chatzisarantis, Culverhouse, \& Biddle, 2003) and intention toward engaging in physical activity (Lim \& Wang, 2009).

From a self-determined perspective, the social context is broadly categorized into two primary themes; autonomy-supportive and controlling (Deci \& Ryan, 1985; Reeve, Jang, Carrell, Jeon, \& Barch, 2004). An autonomy-supportive learning context is perceived by students as teachers who are empathetic, value students internal desires, use language that is not strict (e.g., you could run) and provide students with a voice (Reeve et al., 2004). In addition, autonomy-supportive contexts will provide students with opportunities to demonstrate success and provide a sense of emotional connectedness and safety (Sierens, Vansteenkiste, Goossens, Soenens, \& Dochy, 2009). On the other end of the spectrum, a controlling environment will be pressure filled (e.g., deadlines), use authoritarian language (e.g., you will run), and neglect students who demonstrate negative affect or ideas (Reeve et al., 2004). Teachers can also design and implement a highly controlling setting if they seem disorganized and are emotionally closed and cold (Skinner \& Belmont, 1993).

\section{Social Context and Physical Education}

Within physical education, research on self-determined social contexts has been focused on: (a) interventions to change teacher's abilities to implement a motivationally-supportive context (Chatzisarantis \& Hagger, 2009; Perlman, 2011b; Perlman \& Piletic, 2012; Prusak, Treasure, Darst, \& Pangrazi, 2004; Tessier, Sarrazin, \& Ntoumanis, 2010) and (b) the applied benefits of engaging students in diverse social contexts (Mandigo, Holt, Anderson, \& Sheppard, 2008; Mouratidis, Vansteenkiste, Lens, \& Sideridis, 2008; Murcia, Lacarcel, \& Alvarez, 2010; Ward, Wilkinson, Graser, \& Prusak, 2008). A summary of findings from the aforementioned studies indicate that teachers can be taught to use instructional behaviors that are more autonomy-supportive and that students benefit (e.g., enhanced motivation) from being involved in a highly-autonomy-supportive setting. For instance, teachers engaged in an autonomy-supportive intervention are more likely to adopt and implement a highly autonomy-supportive learning context (Perlman, 2011b; Perlman \& Piletic, 2012; Tessier et al. 2010). In addition, students engaged in a highly autonomy-supportive setting indicated higher levels of enjoyment (Mandigo et al., 2008) and demonstrated more self-regulated behavior (Ward et al., 2008).

Using a physical activity lens, research within physical education has investigated the influence of autonomy-supportive environments on PA and PA intentions based predominantly on a theoretical/conceptual framework (Fortier, Duda, Guerin, \& Teixeira, 2012; Ryan et al., 2009; Teixeira, Palmeira, \& Vansteenkiste, 2012) with a limited number of studies using a more scientific or research based methodology (Hagger et al., 2003, 2005; Lim \& Wang, 2009; Pihu et al., 2008). Each of the theoretical studies supports the notion that engaging students in a highly 
autonomy-supportive context can facilitate engagement in PA. The empirically based studies revealed that an individual's level of perceived autonomy-support is strongly associated with greater, (a) leisure time PA participation (Hagger et al., 2003, 2005; Pihu et al. 2008) and (b) intentions to engage in PA participation (Lim \& Wang, 2009). For instance, Lim and Wang (2009) asked 701 Singapore students aged between 13 and 17 to complete self-report measures of autonomysupport, motivation and intentions toward engaging in physically active behaviors. Findings from this study revealed a strong association between the perception of autonomy-support and the desire to engage in physically activity behavior. It is important to note, that there are studies based within SDT that examine PA (Jaakkola, Liukkonen, Ommundsen, \& Laasko, 2008; Parish \& Treasure, 2003; Ward et al., 2008), yet these studies focus primarily on the association between PA, motivation and specific elements of the social context (e.g., providing choice or perceptions of competence). To date there is limited research that has examined the influence of diverse social contexts based within SDT, on actual in-class PA behaviors within physical education. Therefore, due to the theoretical basis and lack of empirical data, the purpose of this paper was to examine the influence of the social context on students' in-class PA. Specifically, this study was guided by the following research question: "What is the influence of the self-determined social context (autonomy-supportive, controlling and balanced) on students' in-class PA (total and health enhancing)?"

\section{Method}

\section{Participants and Settings}

A total of 84 Year 11/12 secondary physical education students (Mean Age $=16.25$ years, Standard Deviation $=0.33$ years; Male $=40$; Female $=44$ ) were randomly assigned to one of three treatment groups. The school was located in the Midwestern region of the United States and the student body was predominantly Caucasian (94\%). Random assignment of students was conducted by selecting 84 students (Autonomy-supportive; AS, Male $=24$; Female $=24$; Controlling; , Male $=22$; Female $=26$; and Balanced; B, Male $=26 ;$ Female $=22$ ) from a total pool of 279 using a random number generator software package before the school year started. In addition, students enrolled within this school were not provided similar class schedules. For instance, a student would not have the same set of classmates in every class.

For the purpose of this study, a 12-lesson unit of basketball was used. The 12-lesson basketball unit followed a skill-drill-game approach (See Table 1) and used one teacher to deliver all lessons. The intent of using the same instructional approach and teacher was to keep a level of consistency across treatment groups related to variables beyond the social context (e.g., similar content).

\section{Intervention-Manipulation of the Social Context}

Manipulation of the social context followed a three-phase process: (a) teacher training, (b) pilot implementation, and (c) actual implementation. During the teacher training phase, one teacher was taught instructional strategies and techniques for 


\section{Table 1 Block Plan of Basketball Unit}

\begin{tabular}{ll}
\hline Day & Lesson Content \\
\hline 1 & Introduction to Basketball \\
& Game Play (Needs Assessment) \\
& Dribbling \\
& Skill Practice \\
& Game Play (3 v 3) \\
$\mathbf{3}$ & Passing \\
& Skill Practice \\
& Game Play (3 v 3) \\
$\mathbf{4}$ & Shooting \\
& Skill Practice \\
& Game Play (3 v 3) \\
$\mathbf{5}$ & Defense \\
& Skill Practice \\
& Game Play (3 v 3) \\
$\mathbf{6}$ & Defense \\
& Skill Practice \\
& Game Play (3 v 3) \\
& Offense \\
$\mathbf{7}$ & Skill Practice \\
& Game Play (3 v 3) \\
& Offense \\
$\mathbf{8 0 - 1 2}$ & Skill Practice \\
& Game Play (3 v 3) \\
& Team Practice-Shooting, Dribbling and Passing \\
& Skill Practice \\
& Game Play (Round Robin) \\
& Skill Practice \\
& Game Play (Round Robin) \\
\hline &
\end{tabular}

creating an autonomy-supportive, controlling and balanced context. The five-day workshop focused on enhancing the teacher's knowledge of self-determination theory, specifically focused on social context literature. Based on the work of Reeve and colleagues (Reeve, 2006, 2009; Reeve, Bolt, \& Cai, 1999; Reeve \& Jang, 2006; Reeve et al., 2004) and Perlman and Webster (2011), the teacher gained insight into 
specific instructional behaviors that aligned with an autonomy-supportive, controlling and balanced context. For instance, the teacher was taught to, (a) communicate, (b) offer hints and (c) ask questions that can be classified as autonomy-supportive or controlling (Sarrazin, Tessier, Pelletier, Trouilloud, \& Chanal, 2006).

The pilot implementation phase, engaged the teacher in the design, implementation and evaluation of his instruction as it aligned with each specific learning context. The teacher was asked to design a sample 12-lesson basketball block plan using the skill-drill-game approach. Upon completion of the block plan, the teacher developed scripted 12 lesson plans for each treatment group and implemented each lesson with three classes (AS, C and B) unaffiliated with the study. The goal of the pilot study was to ensure that the teacher could provide lessons and a unit that aligned with each specific treatment group. Implementation of the pilot units was deemed acceptable by the researcher as it met the guidelines illustrated in the Treatment Fidelity section of this paper. Finally, the actual implementation phase required the teacher to implement each of the three 12-lesson units with each specific treatment group. Due to scheduling limitations, the order of each group was fixed throughout the study ( $\mathrm{B}, \mathrm{AS}, \mathrm{C}$ respectively).

\section{Treatment Fidelity}

To ensure the social contexts were taught in an appropriate manner, data were collected on: (a) students' perceptions of the social context, (b) student motivation and (c) observation of teacher instruction. In addition, data were collected to examine the degree to which students were provided similar opportunities to engage in PA.

Perceptions of the Social Context. The purpose of using the Learning Climate Questionnaire (LCQ; Standage, Duda, \& Ntoumanis, 2005; Williams \& Deci, 1996) was to provide supportive evidence that students in each context perceived an appropriate level of autonomy-support. Students completed the modified LCQ for use in physical education that requires individuals to rate their level of agreement on 15-items using a 7-point Likert scale (1="strongly disagree"; 7="strongly agree"). Two sample questionnaire items were, (a) I feel that my teacher cares about me as a person and (b) Ifeel that my teacher provides me choices and options. Scores are calculated by averaging ratings on all 15-items to provide an overall perception of autonomy-support within a specific setting. As such, higher scores represent perceptions of more autonomy-support. The LCQ has been identified as possessing high internal consistency and $(\alpha>.90)$ within physical education (Standage et al., 2005).

Student Motivation. The purpose of using the Sport Motivation Scale (SMS; Pelletier et al., 1995) was to examine any motivational changes of students within each context. Students rated their agreement on the short form SMS 15-item 7-point Likert scale (7='strongly agree' and 1='strongly disagree'). The SMS began with the stem Why do you participate in physical education and asked students to rate statements such as Because I must do PE to feel good myself. An overall motivation score is calculated using a three-stage analysis. First, scores are averaged into four motivational subscales: (a) intrinsic motivation, (b) identified regulation, (c) external regulation and (d) amotivation. Second, in order for an overall motivation score to be calculated, mean scores should illustrate a 
simplex-pattern. A simplex pattern occurs when constructs close to each other on the motivational scale (e.g., intrinsic motivation and identified regulation) are scored similarly. Third, the subscales are further analyzed into an overall score of motivation using the following calculation: $((2 *$ intrinsic motivation $)+$ identified regulation)-(external regulation $+\left(2^{*}\right.$ amotivation $)$ ). This modified version of the SMS (for use in physical education) has been identified as valid and reliable within the Ward et al. (2008) study.

Observation of Teacher Instruction. Sarrazin et al. (2006) designed and validated an observational tool for the assessment of autonomy-supportive teacher instruction. Each teacher-student interaction is coded into one of fifteen categories that are defined as autonomy-supportive, controlling or neutral (see Sarrazin et al., 2006, for categories, definitions and examples used within the observational tool). As such, each lesson provides a total frequency of statements that align with autonomy-support, control or neutral contexts (e.g., lesson 1-Autonomysupportive $=22$; Controlling $=29$ ). For the purpose of this study, a $90 \%$ benchmark was established for the AS and C groups, while the B lessons were deemed appropriate when having a 40-60\% balance between autonomy-supportive and controlling statements. Collection and analysis of treatment fidelity data are illustrated later within this paper. Sarrazin et al. (2006) described adequate reliability (.75 alpha) and construct and content validity for use in physical education. The purpose of using this observational tool was to provide support that the teacher implemented behaviors that aligned with the appropriate learning context (e.g., autonomy-supportive, controlling and balanced).

Similar PA Opportunities. Videotaped lessons were analyzed using a modified Task Structure Observational Instrument (Siedentop, 1994) to ensure that students within each treatment group were provided similar opportunities to engage in inclass PA. The protocol followed required coders to observe and record teacher and student behaviors during a 10-s interval ( $5 \mathrm{~s}$ to observe and $5 \mathrm{~s}$ to code). During each interval, the coder was asked to assess whether the majority of students were engaged in one of the following: (a) managerial tasks, (b) instructional tasks, (c) transition or (d) off-task. A random sample of two lessons (lesson three and nine) were viewed and coded by two independent observers. Codes were analyzed and provide the amount of time (i.e., seconds) student spent in each category (e.g., transition) throughout the lesson. To ensure reliability of codes, interrater reliabilities (94\%) were calculated and deemed acceptable.

\section{Data Collection}

The initial step of data collection was obtaining university ethics approval and informed consent from all participants. Those students under the age of 18 were required to obtain parental or guardian approval. Informed consent was obtained before assignment of students to a treatment group. Before the beginning of the school year, parents and students were sent a participant information sheet and consent form to engage in the study. Interested students were asked to come to a short information session that outlined the requirements of the study. Those students interested completed and submitted a consent form during the summer months. During the first and last day of the study, students were asked to complete the LCQ 
and SMS in a classroom setting, which took around 10 minutes to complete. In addition, each lesson was video and audio recorded within the gymnasium using two video cameras to ensure that all areas of the learning environment were visible. To capture all student and teacher interactions, the teacher wore a wireless microphone. The intent of the video and audio recording was to analyze teacher instruction using the observation of teacher instruction tool and to examine that students were provided similar PA opportunities across treatment groups.

PA data were recorded through students wearing an ActiGraph GT1M accelerometer (ActiGraph LLC, Pensacola, FL). The ActiGraph GT1M was worn daily by students and provided data associated with time spent in, (a) moderate-to-vigorous PA (MVPA) and (b) total PA (TPA). Each GT1M was set to collect PA data at 5-s epochs. At the beginning of each day, students would come to class, change into their physical education clothes, and wear the ActiGraph GT1M around their waist. Upon completion of each daily lesson, students would remove their accelerometers before heading into their locker rooms. Data collected with the GT1M were downloaded daily to a laptop computer into the ActiWeb software package. The ActiGraph GT1M is a valid and reliable tool for the assessment of secondary physical education students PA (Trost et al., 2002).

\section{Data Analysis}

Analysis of data were conducted in two phases: (a) fidelity of implementation and (b) influence of social context on PA.

Fidelity of Implementation. The initial phase was to establish fidelity of implementation whereby data from the LCQ and SMS were analyzed using two separate $(3 \times 2)($ Group $\times$ Time $)$ Repeated Measures ANOVAs (adjusted $p \leq .025)$ with partial eta squared effect sizes calculated (Small=.01; Moderate=.06; High=.13). The goal of this analysis was to demonstrate a significant (Group $\times$ Time) interaction effect. For this purpose, data on the AS students' scores (i.e., perception of social context and motivation) were significantly higher when compared with the scores of the students in Group C. In addition, observation data provided support of proper implementation where all daily lessons were coded and scores for the frequency of autonomy-supportive, control and neutral per lesson were calculated. Each lesson was deemed appropriate if it met the aforementioned benchmarks (e.g., 90\% autonomy-supportive statements within each AS lesson). Two independent trained raters coded each lesson and identified teacher-student interactions as autonomy-supportive, controlling or neutral. To ensure reliability of codes, both intra and interrater reliabilities were calculated and deemed acceptable (intra $=97 \%$; inter $=90 \%$ ). Finally, a one-way MANOVA was conducted using the data from the modified task structure observational tool (Siedentop, 1994) using instruction, management, transition and off-task as dependent variables. The goal of this analysis was an insignificant interaction effect that would support that students within each treatment group were provided similar PA opportunities.

Influence of Social Context on PA. PA data were downloaded daily to a computer and analyzed using the ActiWeb software. This software condensed daily lesson data into time spent (i.e., seconds) engaged in MVPA and TPA. To assess the influence of each social context, PA data were averaged into pretest (lesson 
1-6) and posttest (lessons 7-12) dependent variables for both TPA and MVPA. Descriptive statistics (mean and standard deviation) were calculated for both pretest and posttest variables for time spent in TPA and MVPA. To identify whether the individual or group should be the level of analysis, intraclass correlation coefficients (ICCs) were calculated. To examine differences between social context groups, two separate $(3 \times 2)($ Group $\times$ Time $)$ Repeated Measures ANOVAs for MVPA and TPA (adjusted $p \leq .025$ ) were conducted. Tukey post hoc tests were conducted for any significant results to examine where between group differences were located. In addition, significant ANOVAs were plotted to illustrate mean differences.

\section{Results}

Descriptive statistics (means and standard deviations) and reliability (alpha) for pretest and posttest scores for perceptions of the social context (LCQ) and motivation (SMS) are displayed in Table 2. Systematic observation data revealed that all lessons met the prescribed percentage thresholds. Repeated Measures ANOVA analyses revealed a significant interaction effect for both perceptions of the social context, Wilks's $\Lambda=.794, F(1,81)=10.51, p=.000, \eta^{2}=.206$, and motivation, Wilks's $\Lambda=$ $.801, F(1,81)=9.35, p=.003, \eta^{2}=.099$, with the students engaged in the AS group reporting higher perceptions of autonomy-support and motivation compared with the students in both the $\mathrm{C}$ and $\mathrm{N}$ groups. Furthermore, the one-way MANOVA for

Table 2 Descriptive Statistics and Reliability for Perceptions of the Social Context and Motivation

\begin{tabular}{|c|c|c|c|c|c|c|c|c|}
\hline & \multicolumn{2}{|c|}{$\begin{array}{l}\text { Autonomy- } \\
\text { Support }\end{array}$} & \multicolumn{2}{|c|}{ Controlling } & \multicolumn{2}{|c|}{ Balanced } & \multirow[b]{2}{*}{$\alpha$} & \multirow[b]{2}{*}{$R^{2}$} \\
\hline & $M$ & $S D$ & $M$ & $S D$ & $M$ & $S D$ & & \\
\hline \multicolumn{9}{|c|}{ Social Context } \\
\hline Pretest & 3.94 & .78 & 3.96 & .69 & 3.93 & .72 & .88 & -.07 \\
\hline Posttest & 4.67 & 1.01 & 3.70 & .91 & 3.95 & 1.10 & .84 & -.10 \\
\hline \multicolumn{9}{|l|}{ Motivation } \\
\hline Pretest & 3.43 & 3.11 & 3.42 & 3.20 & 3.46 & 3.22 & .88 & -.11 \\
\hline Posttest & 6.22 & 3.44 & 3.11 & 3.80 & 3.43 & 3.23 & .86 & -.18 \\
\hline \multicolumn{9}{|l|}{$T P A$} \\
\hline Pretest & 32.42 & 4.73 & 33.87 & 4.99 & 33.41 & 4.93 & - & -.09 \\
\hline Posttest & 32.43 & 4.98 & 33.97 & 5.24 & 33.09 & 5.36 & - & -.19 \\
\hline \multicolumn{9}{|l|}{$M V P A$} \\
\hline Pretest & 11.84 & 2.06 & 11.60 & 1.86 & 11.47 & 2.63 & - & -.18 \\
\hline Posttest & 15.07 & 3.09 & 12.01 & 2.59 & 12.06 & 3.24 & - & -.24 \\
\hline
\end{tabular}

Note. Time for TPA and MVPA is displayed in minutes. 
opportunities to engage in PA was insignificant, Wilks's $\Lambda=.958, F(4,160)=.868$, $p=.484, \eta^{2}=.021$, providing support that students across treatment groups were provided a similar amount of time to engage in PA. Figures 1 and 2 illustrate group differences for significant social context and motivation results.

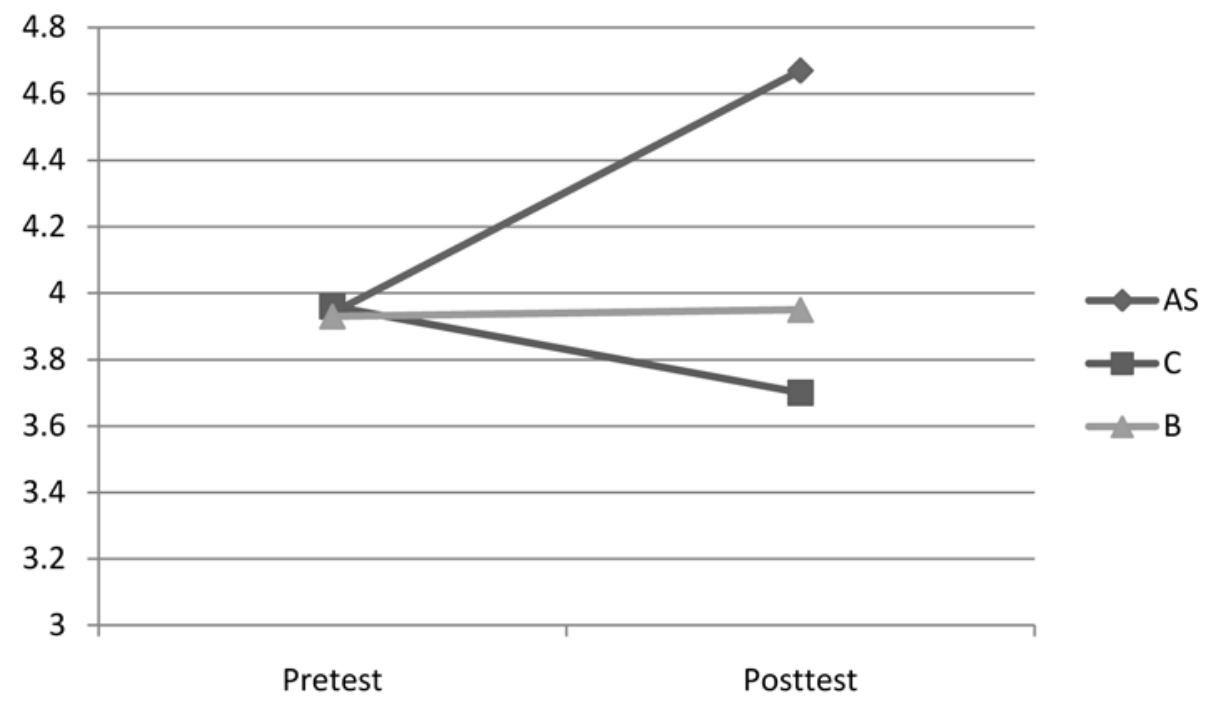

Figure 1 - Mean Score for Perception of Social Context

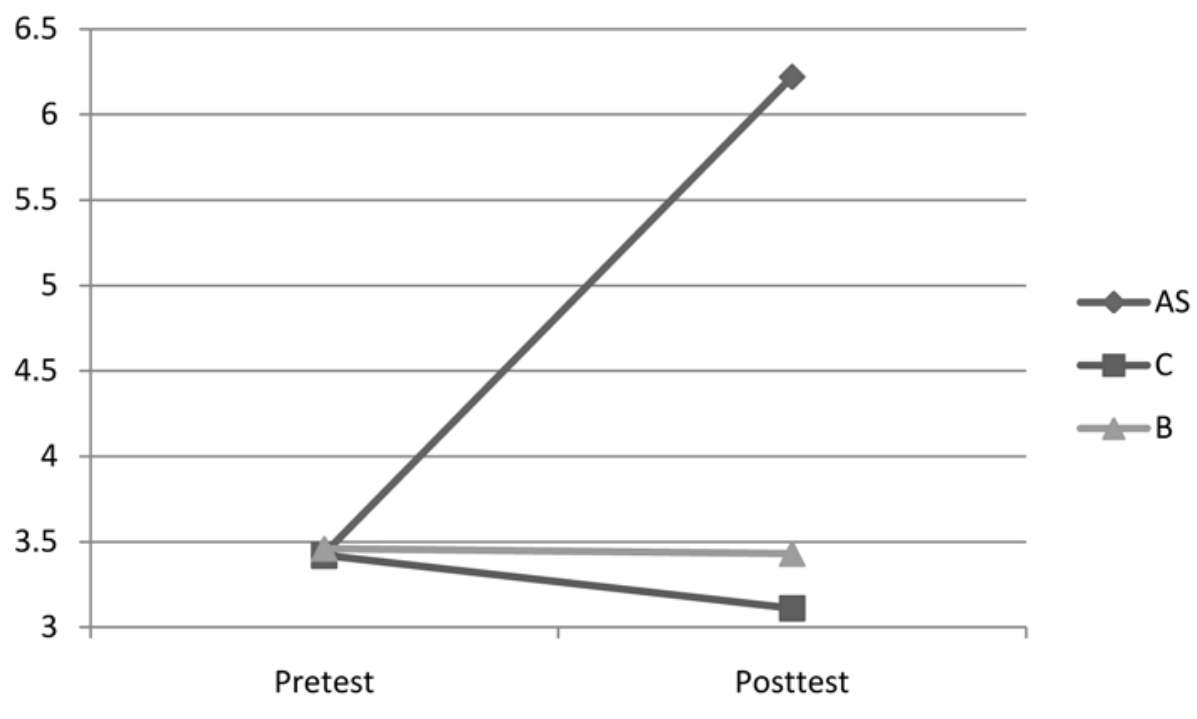

Figure 2 - Mean Score for Student Motivation per Social Context 
ICC calculations revealed the individual as the unit of analysis based on the guidelines of Kenny and LaVoie (1985), whereby negative calculations were revealed for all dependent variables. Descriptive statistics (means and standard deviations) for pretest and posttest PA variables (TPA and MVPA) and ICCs are displayed in Table 2. Repeated Measures ANOVA analyses revealed a significant interaction effect for MVPA, Wilks's $\Lambda=.865, F(2,81)=6.324, p=.003, \eta^{2}=.135$, whereby the AS group was higher compared with the $\mathrm{B}$ and $\mathrm{C}$ groups respectively. In addition, TPA was insignificant, Wilks's $\Lambda=.993, F(2,81)=0.303, p=.740$, $\eta^{2}=.007$. Tukey post hoc results for MVPA are displayed in Table 3 whereby the AS group was significantly different when compared with both the $\mathrm{C}$ and $\mathrm{B}$ groups. In addition, Figure 3 provides an illustration of MVPA mean differences for each social context.

\section{Table 3 Tukey Post Hoc Test Results for MVPA}

\begin{tabular}{|c|c|c|c|c|c|c|}
\hline \multirow[b]{2}{*}{$\begin{array}{l}\text { Treatment } \\
\text { (I) }\end{array}$} & \multirow[b]{2}{*}{$\begin{array}{l}\text { Treatment } \\
\text { (J) }\end{array}$} & \multirow[b]{2}{*}{$\begin{array}{c}\text { Mean Difference } \\
(\mathrm{I}-\mathrm{J})\end{array}$} & \multirow[b]{2}{*}{$\begin{array}{l}\text { Std. } \\
\text { Error }\end{array}$} & \multirow[b]{2}{*}{ Sig. } & \multicolumn{2}{|c|}{ 95\% Confidence Interval } \\
\hline & & & & & $\begin{array}{l}\text { Lower } \\
\text { Bound }\end{array}$ & $\begin{array}{l}\text { Upper } \\
\text { Bound }\end{array}$ \\
\hline \multirow[t]{2}{*}{ AS } & $\mathrm{C}$ & $1.646^{*}$ & .5436 & .009 & .3484 & 2.944 \\
\hline & B & $1.6857 *$ & .5436 & .007 & .3877 & 2.983 \\
\hline $\mathrm{C}$ & $\mathrm{B}$ & 0.0393 & .5436 & .997 & -1.258 & 1.337 \\
\hline
\end{tabular}

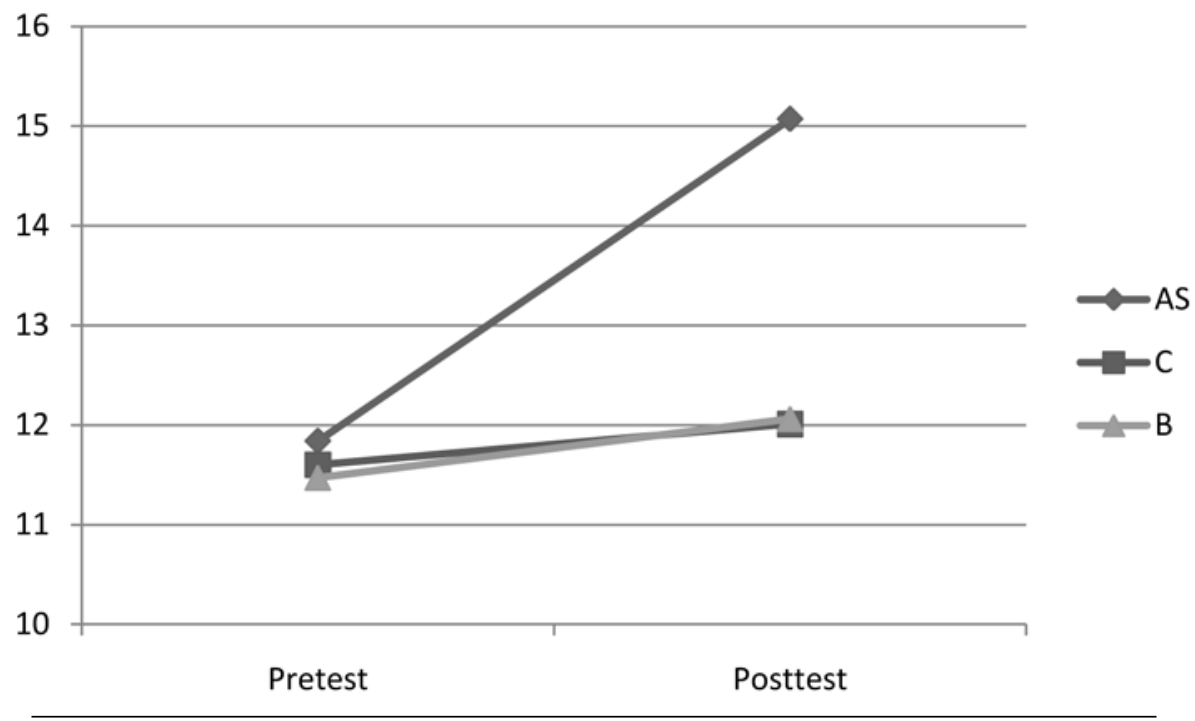

Figure 3 - Mean Time Spent in MVPA per Social Context 


\section{Discussion and Conclusions}

The purpose of this study was to examine the influence of the social context, grounded within self-determination theory, on in-class PA of secondary physical education students. Results indicated that students engaged in the highly autonomysupportive unit of basketball spent significantly more time in health-enhancing levels of PA when compared with the other two groups (Controlling and Balanced). Furthermore, data analysis revealed no difference in terms of students engaging in low intensity levels of PA across contexts.

The results of this study provide empirical evidence supporting the notion that student engagement in an autonomy-supportive learning context can illicit positive outcomes associated with health-enhancing PA. These results support and extend previous studies that demonstrated the applied benefits of engaging students in a highly autonomy-supportive context (Brunel, 1999; Goudas, 1998; Jaakkola et al., 2008). Specifically, this study (a) supports that a highly autonomysupportive context elicits higher levels of health-enhancing MVPA and (b) extends the body of research as it used an objective measure of PA (i.e., accelerometers). Many studies that focused on the self-determined context indicate that support for student autonomy and in turn the influence on student motivation is a primary factor associated with student experiences and outcomes (Jaakkola et al., 2008; Vallerand, 1997, 2001). This study is no different in that regard. There seemed to be three results in this study that could be deemed interesting: (a) group differences in MVPA, (b) lack of group differences in TPA and (c) similarities between the controlling and balanced groups.

The most interesting finding from this study was associated with the significantly higher levels of MVPA demonstrated by students in the AS group. This finding provides empirical support for the theoretical literature indicating that an autonomy-supportive environment can illicit higher levels of PA (Lim \& Wang, 2009; Ryan et al., 2009). A plausible reason for the influence of the context on PA behaviors could be attributed to student's higher levels of motivation. Motivation is a powerful factor associated with student engagement in activity, specifically the intensity each student would put forth in a movement setting (Jaakkola et al., 2008). In addition, as students were engaged in diverse social settings, the highly autonomy-supportive learning context may have been supportive of one or more of their underlying psychological needs of autonomy, competence and relatedness. Deci and Ryan (1985) suggest that a social setting should provide support for all three psychological needs, yet it can still be influential if one need is supported in a significant way. No matter the influence of the social context on one or more of the psychological needs, the end result of influencing student motivation is the key. As such, the instructional strategies used within the AS group were enough to significantly change the motivational levels of the students.

It would seem logical that if students were more motivated, then engagement in terms of TPA would be significantly different. The results of this study do not support this hypothesis, as there were no TPA differences between groups. This lack of significant group differences could be attributed to: (a) each unit of basketball providing a similar amount of time for students to move and (b) motivational influence focusing on the intensity of movement. Since this study was focused on the instructional aspects of the social context and not the design of learning tasks, 
students engaged in similar lesson content. For instance, students in each group were engaged in a passing drill during lesson three. The drill had students moving in the same manner, thus controlling for potential group differences in terms of total amount of PA.

Finally, the similarity between students' TPA and MVPA within the Controlling and Balanced contexts is worth mentioning. It would seem possible that students in the Controlling and Balanced groups may not have perceived as much of a difference. This result supports the notion that teachers may need to be highly supportive to overcome the commonly adopted use of controlling strategies (Reeve, 2009). The level of autonomy-supportive statements within the Controlling (under 10\%) and Balanced (40-60\%) environments may not have been enough to significantly change the PA levels or motivation of students.

The findings from this study demonstrate the important role a teacher plays on the motivation and PA of secondary physical education students. Housed under self-determination theory, manipulation of the instructional communication delivered from the teacher to the student created a motivationally supportive learning context. The social context is the main area that a teacher can have on influencing student motivation (Reeve et al., 2004). Within this study, student perceptions of their motivation and engagement in higher intensity PA were assisted in this regard in only 12 lessons. An important practical concept that could be taken away from this study is that the principles taught to the teacher within the intervention, such as communication, empathy and diverse forms of language, can be a powerful pedagogical tool for making a positive change within secondary physical education.

\section{Implications, Limitations and Future Studies}

The results of this study support that teaching and learning within a highly autonomy-supportive setting can facilitate student motivation and increase PA behaviors. From a practitioner perspective, students may benefit from being taught by a teacher who uses a more autonomy-supportive instructional style. The positive aspect of using autonomy-supportive instruction is that these principles (e.g., communication, hints, etc.) can be layered over a preexisting lesson or unit. As such, teachers can be provided the opportunity to enhance their lessons without detracting from the underlying learning outcomes and lesson objectives. Specific principles and concepts of an autonomy-supportive instructional style are articulated within the general education (Reeve et al., 1999, 2004; Reeve \& Jang, 2006) and the physical education literature (Perlman \& Webster, 2011) to assist teachers in modifying their instruction. Overarching concepts taught within the aforementioned practical articles (e.g., forms of language and demonstration of patience) focus on how a teacher can deliver instruction to support internal motives of students, provide meaning behind learning tasks and demonstrate a level of caring when a student indicates dislike for an activity.

It is important to note that this study is not without limitations. The concept of autonomy support within this project was viewed as a holistic concept, yet there are underlying specific teacher behaviors that influence the overall learning context. These teacher behaviors include concepts such as communication, offering hints and acknowledging affect. The results of this study do not provide such a micro analysis and lead into a need for future inquiry. The fixed order of each treatment 
group may have influenced the influenced students' MVPA and TPA. In addition, there is a need for future studies that examine diverse outcomes and experiences of physical education students when engaged in different social contexts. Physical education literature may benefit from additional studies that implement various instructional approaches, beyond skill-drill-games, that may provide more opportunities to engage in PA.

\section{References}

Brunel, P. (1999). Relationship between achievement goal orientations and perceived motivational climate on intrinsic motivation. Scandinavian Journal of Medicine \& Science in Sports, 9, 365-374.

Chatzisarantis, N.L.D., \& Hagger, M.S. (2009). Effects of an intervention based on selfdetermination theory on self-reported leisure-time physical activity participation. Psychology \& Health, 24, 29-48. doi:10.1080/08870440701809533

Deci, E.L., \& Ryan, R.M. (1985). Intrinsic motivation and self-determination in human behavior. New York, NY: Plenum.

Edmunds, J., Ntoumanis, N., \& Duda, J.L. (2006). A test of self-determination theory in the exercise domain. Journal of Applied Social Psychology, 36, 2240-2265. doi:10.1111/ j.0021-9029.2006.00102.x

Fortier, M.S., Duda, J.L., Guerin, E., \& Teixeira, P.J. (2012). Promoting physical activity: Development and testing of self-determination theory-based interventions. The International Journal of Behavioral Nutrition and Physical Activity, 9, 1-14. doi:10.1186/1479-5868-9-20

Goudas, M. (1998). Motivational climate and intrinsic motivation of young basketball players. Perceptual and Motor Skills, 86, 323-327. doi:10.2466/pms.1998.86.1.323

Hagger, M.S., Chatzisarantis, N.L.D., Barkpukis, V., Wang, C.K.J., \& Baranowski, J. (2005). Perceived autonomy support in physical education and leisure-time physical activity: A cross-cultural evaluation of the trans-contextual model. Journal of Educational Psychology, 97, 376-390. doi:10.1037/0022-0663.97.3.376

Hagger, M.S., Chatzisarantis, N., Culverhouse, T., \& Biddle, S.J.H. (2003). The processes by which perceived autonomy support in physical education promotes leisure-time physical activity intentions and behaviour: A trans-contextual model. Journal of Educational Psychology, 95, 787-795. doi:10.1037/0022-0663.95.4.784

Jaakkola, T., Liukkonen, J., Ommundsen, Y., \& Laakso, T. (2008). The relationships between situational and contextual self-determined motivation and physical activity intensity as measured by heart rates during ninth grade students' physical education classes. European Physical Education Review, 13, 13-31. doi:10.1177/1356336X07085707

Kenny, D.A., \& La Voie, L. (1985). Separating individual and group effects. Journal of Personality and Social Psychology, 48, 339-348. doi:10.1037/0022-3514.48.2.339

Lim, B.S., \& Wang, C.K. (2009). Perceived autonomy support, behavioural regulations in physical education and physical activity intention. Psychology of Sport and Exercise, 10, 52-60. doi:10.1016/j.psychsport.2008.06.003

Mandigo, J., Holt, N., Anderson, A., \& Sheppard, J. (2008). Children's motivational experiences following autonomy-supportive games lessons. European Physical Education Review, 14, 407-425. doi:10.1177/1356336X08095673

Mouratidis, A., Vansteenkiste, M., Lens, W., \& Sideridis, G. (2008). The motivating role of positive feedback in sport and physical education: Evidence for a motivational model. Journal of Sport \& Exercise Psychology, 30, 240-268.

Murcia, J.A.M., Lacarcel, J.A.V., \& Alvarez, F.D. (2010). Search for autonomy in motor task learning in physical education university students. European Journal of Psychology of Education, 25, 37-47. doi:10.1007/s10212-009-0008-7 
Parish, L.E., \& Treasure, D.C. (2003). Physical activity and situational motivation in physical education: Influence of the motivational climate and perceived ability. Research Quarterly for Exercise and Sport, 74, 173-182.

Pelletier, L.G., Fortier, M.S., Vallerand, R.J., Tuson, K.M., Briere, N.M., \& Blais, M.R. (1995). Toward a new measure of intrinsic motivation, extrinsic motivation, and amotivation in sports: The sport motivation scale (SMS). Journal of Sport \& Exercise Psychology, 17, 35-53.

Perlman, D.J. (2011a). Examination of self-determined motivation within the sport education model. Asia-Pacific Journal of Health. Sport and Physical Education, 2, 79-96.

Perlman, D.J. (2011b). The influence of an autonomy-supportive intervention on preservice teacher instruction: A self-determined perspective. Australian Journal of Teaching Education, 36(11), Article 6.

Perlman, D.J., \& Goc Karp, G. (2010). A self-determined perspective of the sport education model. Physical Education and Sport Pedagogy, 15(4), 401-418. doi:10.1080/17408980903535800

Perlman, D.J., \& Piletic, C. (2012). The influence of an adapted physical education course on preservice teacher instruction: Using a self-determination lens. Australian Journal of Teacher Education, 37(1), Article 1.

Perlman, D.J., \& Webster, C.A. (2011). Supporting student autonomy in physical education. Journal of Physical Education, Recreation \& Dance, 82(5), 46-49.

Pihu, M., Hein, V., Koka, A., \& Hagger, M.S. (2008). How students' perceptions of teachers' autonomy-supportive behaviours affect physical activity behaviour: An application of the trans-contextual model. European Journal of Sport Science, 8, 193-204. doi:10.1080/17461390802067679

Prusak, K.A., Treasure, D.C., Darst, P.W., \& Pangrazi, R.P. (2004). The effects of choice on the motivation of adolescent girls in physical education. Journal of Teaching in Physical Education, 23, 19-29.

Reeve, J. (2006). Teachers as facilitators: What autonomy-supportive teachers do and why their students benefit. The Elementary School Journal, 106(3), 225-236. Reeve, J. (2009). Why teachers adopt a controlling motivational style toward students and how they can become more autonomy supportive. Educational Psychologist, 44(3), 159-175. doi: $10.1080 / 00461520903028990$

Reeve, J. (2009). Why teachers adopt a controlling motivating style toward students and how they can become more autonomy supportive. Educational Psychologist 44, 159-75.

Reeve, J., Bolt, E., \& Cai, Y. (1999). Autonomy-supportive teachers: How they teach and motivate students. Journal of Educational Psychology, 91, 537-548. doi:10.1037/00220663.91.3.537

Reeve, J., \& Jang, H. (2006). What teachers say and do to support students' autonomy during a learning activity. Journal of Educational Psychology, 98, 209-218. doi:10.1037/00220663.98.1.209

Reeve, J., Jang, H., Carrell, D., Jeon, S., \& Barch, J. (2004). Enhancing students' engagement by increasing teachers' autonomy support. Motivation and Emotion, 28(2), 147-169. doi:10.1023/B:MOEM.0000032312.95499.6f

Ryan, R.M., Williams, G.C., Patrick, H., \& Deci, E.L. (2009). Self-determination theory and physical activity: The dynamics of motivation in development and wellness. Hellenic Journal of Psychology, 6, 107-124.

Sarrazin, P.G., Tessier, D.P., Pelletier, L.G., Trouilloud, D.O., \& Chanal, J.P. (2006). The effects of teachers' expectations about students' motivation on teachers' autonomysupportive and controlling behaviors. International Journal of Sport and Exercise Psychology, 4, 283-301.

Siedentop, D. (1994). Task structure observation system. In M. O'Sullivan (Ed.), Technical manual for high school physical education teachers: Their world of work (pp. 18-28). Columbus, OH: Ohio State University. 
Sierens, E., Vansteenkiste, M., Goossens, L., Soenens, B., \& Dochy, F. (2009). The synergistic relationship of perceived autonomy support and structure in the rediction of self-regulated learning. The British Journal of Educational Psychology, 79, 57-68. doi:10.1348/000709908X304398

Skinner, E.A., \& Belmont, M.J. (1993). Motivation in the classroom: Reciprocal effects of teacher behavior and student engagement across the school year. Journal of Educational Psychology, 85, 571-581. doi:10.1037/0022-0663.85.4.571

Standage, M., Duda, J.L., \& Ntoumanis, N. (2005). A test of self-determination theory in school physical education. The British Journal of Educational Psychology, 75(3), 411-433. doi:10.1348/000709904X22359

Tessier, D., Sarrazin, P., \& Ntoumanis, N. (2010). The effect of an intervention to improve newly qualified teachers' interpersonal style, students motivation and psychological need satisfaction in sport-based physical education. Contemporary Educational Psychology, 35, 242-253. doi:10.1016/j.cedpsych.2010.05.005

Teixeira, P.J., Palmeira, A.L., \& Vansteenkiste, M. (2012). The role of self- determination theory and motivational interviewing in behavioral nutrition, physical activity, and health: An introduction to the IJBNPA special series. The International Journal of Behavioral Nutrition and Physical Activity, 9, 1-3. doi:10.1186/1479-5868-9-1

Trost, S.G., Pate, R.R., Sallis, J.F., Freedson, P.S., Taylor, W.C., Dowda, M., \& Sirard, J. (2002). Age and gender differences in objectively measured physical activity in youth. Medicine and Science in Sports and Exercise, 34, 350-355. doi:10.1097/00005768200202000-00025

US Department of Health and Human Services. (2010). Strategies to improve the quality of physical education. Washington, DC: US Department of Health and Human Services.

Vallerand, R.J. (1997). Toward a hierarchical model of intrinsic and extrinsic motivation. In M.P. Zanna (Ed.), Advances in experimental social psychology (Vol. 29, pp. 271-360). New York, NY: Academic Press.

Vallerand, R.J. (2001). A hierarchical model of intrinsic and motivation in sport and exercise. In G.C. Roberts (Ed.), Advances in motivation in sport and exercise (pp. 263-320). Champaign, IL: Human Kinetics.

Vallerand, R.J., \& Losier, G.F. (1999). An integrative analysis of intrinsic and extrinsic motivation in sport. Journal of Applied Sport Psychology, 11, 142-169. doi:10.1080/10413209908402956

Ward, J., Wilkinson, C., Graser, S.V., \& Prusak, K.A. (2008). Effects of choice on student motivation and physical activity behavior in physical education. Journal of Teaching in Physical Education, 27, 385-398.

Watts, K., Jones, T.W., Davis, E.A., \& Green, D. (2005). Exercise training in obese children and adolescents. Sports Medicine (Auckland, N.Z.), 35, 375-392. doi:10.2165/00007256200535050-00002

Williams, G.C., \& Deci, E.L. (1996). Internalization of biopsychosocial values by medical students: A test of self-determination theory. Journal of Personality and Social Psychology, 70, 767-779. doi:10.1037/0022-3514.70.4.767 